\title{
A Parametric Analysis on the Vulnerability of Internally Insulated Solid Masonry Walls to Rot Damage
}

\author{
Eirini Mantesi $^{\mathrm{a}^{*}}$, David Allinson ${ }^{\mathrm{a}}$, Roel Tersteeg ${ }^{\mathrm{a}}$ \\ ${ }^{a}$ Building Energy Research Group, School of Architecture, Building and Civil Engineering, Loughborough University, Loughborough, United Kingdom
}

\begin{abstract}
This paper investigates the risk of rot damage in brick solid masonry walls (SMWs) before and after they have received an Internal Wall Insulation (IWI) system. One-dimensional simulations in Delphin were calibrated against laboratory experiments of full-scale insulated and uninsulated SMW assemblies in the Hygrothermal Test Facility. A parametric analysis was conducted to assess the sensitivity of the walls to a list of scenario uncertainties. The results indicated that in all Test Cases (TCs) the risk of rot damage increased when internal insulation is retrofitted to a SMW.
\end{abstract}

Peer-review under the responsibility of the organizing committee of the ICMB21.

Keywords: Solid Masonry Walls, Intenal Wall Insulation; Retrofit; Rot Damage; Parametric Analysis

\section{Introduction and Research Aim}

A significant number of existing houses have limited or no insulation altogether. Brick built solid masonry wall (SMW) construction, a key feature of pre-1919 construction in the UK, account for around 30\% of the building stock [1]. Therefore, retrofitting insulation to SMWs would make a significant contribution to the UK's greenhouse gas emission reduction targets. Applying internal wall insulation reduces the temperature of the masonry, the rate of wetting and drying, and the locations where water vapour might condense and accumulate. Therefore, the aim of this short paper is to assess the risk of rot damage in SMWs before and after they have been retrofitted with IWI. The research objectives include reviewing existing literature to define suitable risk assessment criteria for rot damage, comparing the performance of the insulated and uninsulated SMWs and investigating the impact of scenario uncertainties on rot risk assessment.

\subsection{Methodology}

Two walls have been used as the case studies in this analysis, an uninsulated SMW, representative of existing English housing stock (215mm high absorbent brick with lime plaster internal finish) and the same SMW which has been retrofitted internally with an insulated plasterboard (phenolic insulation core with $12.5 \mathrm{~mm}$ plasterboard bonded to its front surface). Details of the two walls are shown in Figure 1.

a)

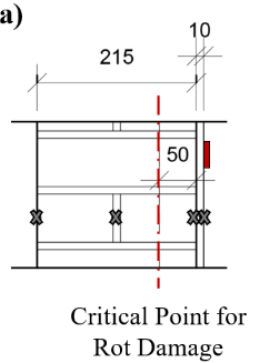

b)

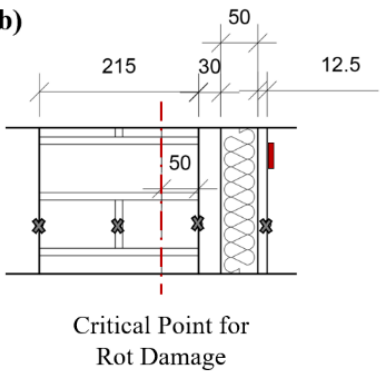

\author{
Measurement \\ Sensors: \\ ¿ Temperature and RH: \\ Thermocouples Type T \& \\ Honeywell HIH-4000 \\ I Heat Flow Rate: \\ Hukseflux HFP03-05
}

Figure 1. Construction details, measurement locations and critical point for rot damage risk assessment: a) SMW, b) IWI

Prior to running any computational analysis, the two wall segments were constructed and tested using the Hygrothermal Test Facility (HTF). The collected data were used to calibrate the simulation models against three thermal and two hygric material properties, thermal conductivity $(\lambda)$, bulk density $(\rho)$ and specific heat capacity $(c)$, the water vapor diffusion resistance factor $(\mu)$ and the water uptake coefficient $(\alpha \mathrm{w})$. All simulation models were created using DELPHIN, version 5.9. Both walls were modelled using one-dimensional simulation as this was deemed to be an acceptable simplification, based on the findings of previous studies

\footnotetext{
* Corresponding author. Telephone Number: +44 (0) 1509226195, Email: E.Mantesi@lboro.ac.uk
} 
$[2,3]$. The internal boundary conditions were calculated based on external air temperatures, using the correlations specified in BS EN 15026 [4]. The external boundary conditions were specified using historic hourly weather data, as recorded by the MET office MIDAS database for twelve years [5]. Four locations were selected for the analysis, according to the wind-driven rain (WDR) exposure zones, as specified in BS 8104:1992 [6]. The risk of rot was assessed at $5 \mathrm{~cm}$ depth from the internal surface of the masonry layer (to consider rot in timber joists as described in [7]) (as shown in Figure 1). The presence of liquid water is possible above a $\mathrm{RH}$ of $95 \%[3,7]$ and this was used as the threshold for risk. A parametric analysis was performed to reflect on the implications of wall orientation and exposure to WDR. Details on the different Test Cases (TC) can be found in Table 1.

\subsection{Results}

The results of the parametric analysis indicated that the number of hours when the SMW was exposed to RH $>95 \%$ was higher for the insulated wall (Table 1). Looking at the impact of orientation (TC1-TC4), the results were different for the two walls. For the uninsulated SMW the worst orientation was West, followed by North. In the case of insulated SMW, South orientation was found to be the worst-case scenario, followed closely by West. This finding verifies that relying solely on a single orientation (for the worst-case scenario), can potentially lead to an underestimation of risk, something which is also confirmed in other previous studies [3,8]. TC1 and TC5-7 compared the impact of WDR exposure to risk. As expected, both walls were found to be significantly more vulnerable in the severe and very severe WDR exposure zones. The insulated SMW was also found to have a higher risk for the sheltered and moderate exposure to WDR.

Table 1. Results of parametric analysis for moisture risk assessment and TC description. Number of hours and relative duration when the walls are exposed to increased rot damage risk for the 10-years' analysis.

\begin{tabular}{|c|c|c|c|c|c|}
\hline \multirow[t]{2}{*}{ Test Cases } & \multirow[t]{2}{*}{ Test Cases Description } & \multicolumn{2}{|c|}{ SMW } & \multicolumn{2}{|c|}{ IWI } \\
\hline & & (Hrs) & $(\%)$ & (Hrs) & $(\%)$ \\
\hline TC1 & West orientation, moderate WDR exposure, high internal moisture production rate & 1076 & $1.23 \%$ & 22211 & $25.35 \%$ \\
\hline TC2 & North orientation, moderate WDR exposure, high internal moisture production rate & 854 & $0.97 \%$ & 13090 & $14.94 \%$ \\
\hline TC3 & East orientation, moderate WDR exposure, high internal moisture production rate & 551 & $0.63 \%$ & 13194 & $15.06 \%$ \\
\hline TC4 & South orientation, moderate WDR exposure, high internal moisture production rate & 643 & $0.73 \%$ & 25479 & $29.08 \%$ \\
\hline TC5 & West orientation, sheltered WDR exposure, high internal moisture production rate & 0 & $0 \%$ & 30569 & $34.89 \%$ \\
\hline TC6 & West orientation, severe WDR exposure, high internal moisture production rate & 11834 & $13.50 \%$ & 63133 & $72.06 \%$ \\
\hline TC7 & West orientation, very severe WDR exposure, high internal moisture production rate & 30778 & $35.13 \%$ & 80697 & $92.12 \%$ \\
\hline
\end{tabular}

\subsection{Discussion and Conclusions}

The risk of rot damage increases when internal wall insulation is retrofitted to a SMW. Therefore, more robust methods of risk assessment are required to ensure that this is done safely. This paper marks a first step towards that goal. Orientation of the wall is important, and calibration and verification of simulated results using the Hygrothermal Test Facility was beneficial. The 95\% threshold of RH may overestimate risk. Further work should explore the three-dimensional moisture transport issues through timber joints in SMWs.

\section{Acknowledgements}

This research was made possible by Engineering and Physical Sciences Research Council (EPSRC) support for the research project: Methods and Metrics for Moisture Risk Assessment - Solid Wall Insulation (MRA-SWI) (grant EP/R008329/1). The Hygrothermal Test Facility was funded by a capital equipment grant from the UK Department for Energy and Climate Change.

\section{References}

[1] Ministry of Housing, Communities \& Local Government. (2016). English Housing Survey: Technical Report. London.

[2] E. Vereecken, S. Roels, Hygric performance of a massive masonry wall: How do the mortar joints influence the moisture flux?, Construction and Building Materials, 41 (2013) 697-707. doi:10.1016/j.conbuildmat.2012.12.024

[3] V. Marincioni, G. Marra, H. Altamirano-Medina. (2018). Development of predictive models for the probabilistic moisture risk assessment of internal wall insulation, Building and Environment, (137) 257-267. doi:10.1016/j.buildenv.2018.04.001.

[4] British Standards Institution, BS EN 15026:2007. Hygrothermal performance of building components and building elements - Assessment of moisture transfer by numerical simulation. London.

[5] MET office, MIDAS - Met Office Integrated Data Archive System, (n.d.)

[6] British Standards Institution, BS EN 8104: 1992. Code of practice for assessing exposure of walls to wind-driven rain. London.

[7] E. Vereecken, L. Van Gelder, H. Janssen, S. Roels. (2015). Interior insulation for wall retrofitting - A probabilistic analysis of energy savings and hygrothermal risks, Energy and Buildings, (89) 231-244. doi:10.1016/j.enbuild.2014.12.031.

[8] Ministry of Housing, Communities \& Local Government. (2019). Research into resistance to moisture in buildings. London. 